\title{
PROYEKSI PENJUALAN MOTOR YAMAHA PADA PT.SENTRAL YAMAHA PALU MENGGUNAKAN METODE TREND ANALISIS
}

\author{
Nurwahyuni ${ }^{1}$, A. I. Jaya ${ }^{2}$ dan Resnawati ${ }^{3}$ \\ 1,2,3 Program Studi Matematika Jurusan Matematika FMIPA Universitas Tadulako \\ Jalan Soekarno-Hatta Km. 09 Tondo, Palu 94118, Indonesia \\ 1nurwahyuni.1994@yahoo.com, 2jayaindraagus@gmail.com, 3r35n4w4t1@yahoo.com
}

\section{ABSTRACT}

Trend analysis is a method to perform an estimate of the future where in this study is used as a method to obtain the sales projection of motorcycle. The problem in this research are how to project the sales of motorcycle using Trend Analysis and how much profit of PT. Yamaha Sentral Palu. The purposes of this research are to have the sales projection of each type of motorcycles from January to December in 2016 using Ternd Analysis method and to have the profit of PT. Yamaha Sentral Palu. The results showed that projection error value is $9,7 \%$ for matic motorcycle, $11,06 \%$ for sport motorcycle and $12,1 \%$ for motorcycle. The profits have increased each month since January - December 2016 amounted respectively Rp.269.000.000, Rp.270.000.000, Rp.273.000.000, Rp.273.000.000, Rp.277.000.000, Rp.277.000.000， Rp.281.000.000， Rp.281.000.000， Rp.285.000.000， Rp. 285.000.000, Rp. 289.000.000, Rp.289.000.000.

Keywords : Projection, Relative Error, Trend Analysis.

\section{ABSTRAK}

Trend Analisis merupakan suatu metode untuk melakukan suatu estimasi pada masa yang akan datang dimana dalam penelitian ini digunakan sebagai metode untuk memperoleh proyeksi jumlah penjualan motor. Masalah yang diajukan dalam penelitian ini adalah bagaimana memproyeksi penjualan motor menggunakan metode Trend Analisis dan berapa keuntungan PT. Sentral Yamaha Palu. Tujuan penelitian adalah mendapatkan proyeksi penjualan setiap tipe motor yamaha dari bulan Januari sampai Desember di tahun 2016 menggunakan metode Ternd Analisis dan besarnya keuntungan yang diperoleh PT. Sentral Yamaha Palu. Dari hasil perhitungan menggunakan Trend analisis diperoleh proyeksi dengan nilai galat yaitu 9,7\% untuk motor matik, 11,06\% untuk motor sport dan $12,1 \%$ untuk motor bebek. Adapun keuntungan yang diperoleh mengalami peningkatan setiap bulannya sejak bulan januari - desember tahun 2016 sebesar masing-masing Rp. 269.000.000, Rp. 270.000.000, Rp.273.000.000, Rp.273.000.000, Rp.277.000.000， Rp.277.000.000， Rp.281.000.000， Rp.281.000.000, Rp. 285.000.000, Rp. 285.000.000, Rp.289.000.000, Rp.289.000.000.

Kata Kunci : Proyeksi, Galat Relatif, Trend Analisis. 


\section{PENDAHULUAN}

\subsection{Latar Belakang}

Sepeda motor merupakan salah satu kendaraan yang paling banyak digunakan masyarakat, baik dari kalangan bawah, menengah, maupun atas. Pemilihan tersebut didasarkan atas harga beli motor yang semakin murah dan terjangkau oleh masyarakat. Hal ini merupakan salah satu penyebab semakin meningkatnya penjualan motor Yamaha dari tahun ke tahun (Wignjosoebroto dalam Wibowo,2008). Perusahaan PT. Sentral Yamaha Palu bergerak dibidang penjualan motor, service, dll. Pemasaran motor yang tidak menentu membuat perusahaan sulit untuk mengendalikan persediaan sehingga diperlukan perencanaan penjualan untuk meminimumkan kekurangan persediaan. Perencanaan dimulai dengan memproyeksikan penjualan motor. Perencanaan produksi ini merupakan alat komunikasi antara manajemen teras (top management) dan manufaktur (Ginting, 2007).Dalam penelitian ini motor Yamaha yang dibahas terdiri dari motor matik, motor bebek, dan motor sport.

Untuk keperluan proyeksi digunakan metode Trend analisis yang merupakan salah satu model data berkala (time series) (Fitria Sari, 2009). Metode Trend Analisis merupakan salah satu metode pemecahan masalah-masalah dalam penaksiran (Vera Devani, 2010). Perhitungan nilai trend dapat dilakukan dengan beberapa metode, tetapi yang digunakan dalam penelitian ini adalah metode kuadrat terkecil (least squre method) bertujuan mendapatkan penaksiran koefisien yang menjadikan jumlah kuadrat error sekecil mungkin (Makridakis, 1999).

\subsection{Rumusan Masalah}

Rumusan masalah penelitian ini adalah bagaimana memproyeksi penjualan motor yamaha menggunakan metode Trend Analisis dan berapa keuntungan yang diperoleh PT. Sentral Yamaha Palu tahun 2016.

\subsection{Batasan Penelitian}

1. Penjualan motor yang diteliti hanya sebatas di PT. Sentral Yamaha Palu

2. Penjualan motor yang diteliti terdiri dari motor matic, motor bebek, dan motor sport.

3. Penjualan motor yang diteliti adalah penjualan yang dilakukan secara tunai

\section{METODE PENELITIAN}

Langkah-langkah yang dilakukan dalam penelitian ini yaitu

1. Memulai penelitian.

2. Mengkaji literatur.

3. Pengambilan data

4. Uji Lineritas 
5. Proyeksi menggunakan metode trend analisis

6. Kesimpulan

7. Selesai

III. HASIL DAN PEMBAHASAN

\subsection{Pengambilan Data}

Adapun data yang di peroleh dari PT. Sentral Yamaha Palu Sebagai Berikut :

1. Data Penjualan Motor Matik, Motor Bebek dan Motor Sport

Tabel 1 : Penjualan Motor Matik, Motor Bebek dan Motor Sport Tahun 2013-2015

\begin{tabular}{|c|c|c|c|c|c|c|c|c|c|}
\hline \multirow{2}{*}{ Tahun } & \multirow{2}{*}{ Bulan } & \multirow{2}{*}{$\begin{array}{l}\text { Indeks } \\
\text { Waktu } \\
(X)\end{array}$} & \multirow{2}{*}{$X^{2}$} & \multicolumn{2}{|c|}{ Motor Matik } & \multicolumn{2}{|c|}{ Motor Bebek } & \multicolumn{2}{|c|}{ Motor Sport } \\
\hline & & & & Y & $X . Y$ & $Y$ & $X . Y$ & Y & $X . Y$ \\
\hline \multirow{12}{*}{2013} & Januari & 1 & 1 & 77 & 77 & 65 & 65 & 22 & 22 \\
\hline & Februari & 2 & 4 & 87 & 174 & 71 & 142 & 29 & 58 \\
\hline & Maret & 3 & 9 & 68 & 204 & 44 & 132 & 25 & 75 \\
\hline & April & 4 & 16 & 69 & 276 & 56 & 224 & 23 & 92 \\
\hline & Mei & 5 & 25 & 74 & 370 & 68 & 340 & 32 & 160 \\
\hline & Juni & 6 & 36 & 84 & 504 & 67 & 402 & 34 & 204 \\
\hline & Juli & 7 & 49 & 80 & 560 & 76 & 532 & 28 & 196 \\
\hline & Agustus & 8 & 64 & 87 & 696 & 73 & 584 & 31 & 248 \\
\hline & september & 9 & 81 & 70 & 630 & 77 & 693 & 29 & 261 \\
\hline & Oktober & 10 & 100 & 64 & 640 & 60 & 600 & 39 & 390 \\
\hline & November & 11 & 121 & 92 & 1012 & 77 & 847 & 34 & 374 \\
\hline & Desember & 12 & 144 & 83 & 996 & 82 & 984 & 34 & 408 \\
\hline \multirow{12}{*}{2014} & Januari & 13 & 169 & 81 & 1053 & 64 & 832 & 34 & 442 \\
\hline & Februari & 14 & 196 & 83 & 1162 & 82 & 1148 & 32 & 448 \\
\hline & Maret & 15 & 225 & 79 & 1185 & 67 & 1005 & 39 & 585 \\
\hline & April & 16 & 256 & 63 & 1008 & 55 & 880 & 37 & 592 \\
\hline & Mei & 17 & 289 & 69 & 1173 & 58 & 986 & 31 & 527 \\
\hline & Juni & 18 & 324 & 85 & 1530 & 72 & 1296 & 44 & 792 \\
\hline & Juli & 19 & 361 & 116 & 2204 & 91 & 1729 & 27 & 513 \\
\hline & Agustus & 20 & 400 & 97 & 1940 & 79 & 1580 & 36 & 720 \\
\hline & september & 21 & 441 & 99 & 2079 & 74 & 1554 & 38 & 798 \\
\hline & Oktober & 22 & 484 & 86 & 1892 & 82 & 1804 & 41 & 902 \\
\hline & November & 23 & 529 & 82 & 1886 & 80 & 1840 & 49 & 1127 \\
\hline & Desember & 24 & 576 & 107 & 2568 & 98 & 2352 & 32 & 768 \\
\hline \multirow{7}{*}{2015} & Januari & 25 & 625 & 92 & 2300 & 72 & 1800 & 39 & 975 \\
\hline & Februari & 26 & 676 & 84 & 2184 & 76 & 1976 & 44 & 1144 \\
\hline & Maret & 27 & 729 & 91 & 2457 & 63 & 1701 & 37 & 999 \\
\hline & April & 28 & 784 & 78 & 2184 & 59 & 1652 & 48 & 1344 \\
\hline & Mei & 29 & 841 & 90 & 2610 & 79 & 2291 & 40 & 1160 \\
\hline & Juni & 30 & 900 & 99 & 2970 & 78 & 2340 & 46 & 1380 \\
\hline & Juli & 31 & 961 & 81 & 2511 & 92 & 2852 & 33 & 1023 \\
\hline
\end{tabular}




\begin{tabular}{|l|l|c|c|c|c|c|c|c|c|} 
& Agustus & 32 & 1024 & 82 & 2624 & 84 & 2688 & 41 & 1312 \\
\cline { 2 - 10 } & september & 33 & 1089 & 79 & 2607 & 91 & 3003 & 53 & 1749 \\
\cline { 2 - 10 } & Oktober & 34 & 1156 & 83 & 2822 & 73 & 2482 & 39 & 1326 \\
\cline { 2 - 10 } & November & 35 & 1225 & 103 & 3605 & 69 & 2415 & 41 & 1435 \\
\cline { 2 - 10 } & Desember & 36 & 1296 & 92 & 3312 & 92 & 3312 & 45 & 1620 \\
\hline & Total & 666 & 16206 & 3,036 & 58005 & 2646 & 51063 & 1.306 & 26169 \\
\hline
\end{tabular}

Sumber : (PT.Sentral Yamaha Palu Tahun 2016)

2. Keutungan perusahaan

Tabel 2 : Keuntungan Perusahaan

\begin{tabular}{|l|c|}
\hline Tipe Motor & Keuntungan (Rp/unit) \\
\hline Matik & 1.000 .000 \\
\hline Bebek & 1.000 .000 \\
\hline Sport & 2.000 .000 \\
\hline
\end{tabular}

Sumber : (PT.Sentral Yamaha Palu Tahun 2016)

\subsection{Uji Lineiraritas}

Penentuan metode trend analisis diperoleh melalui tahap pengujian yaitu uji linearitas data. Pengujian linearitas data penjualan motor sebagai berikut

a. Motor Matik

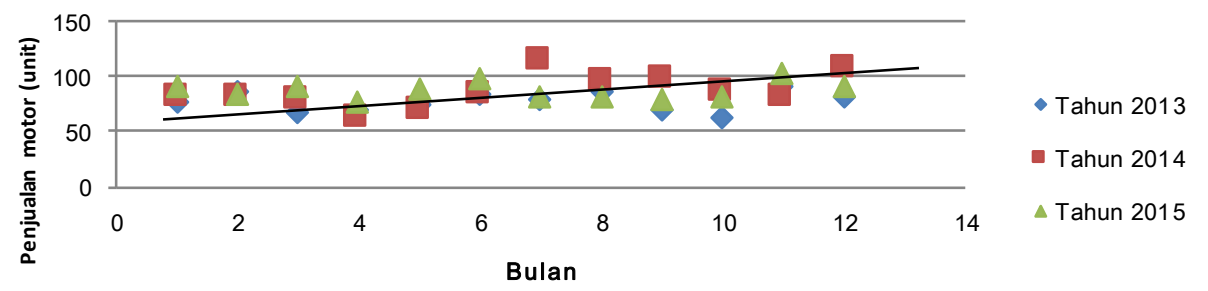

Gambar 1 : Plot Data Aktual Penjualan Motor Matik

b. Motor Bebek

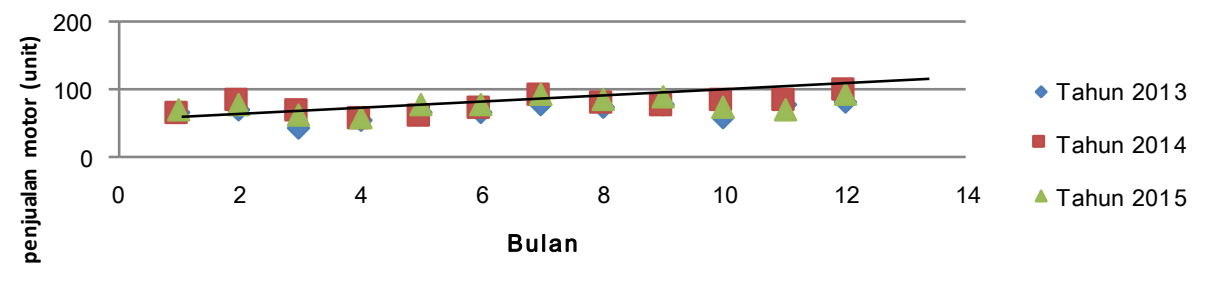

Gambar 2 : Plot Data Aktual Penjualan Motor Bebek 
c. Motor Sport

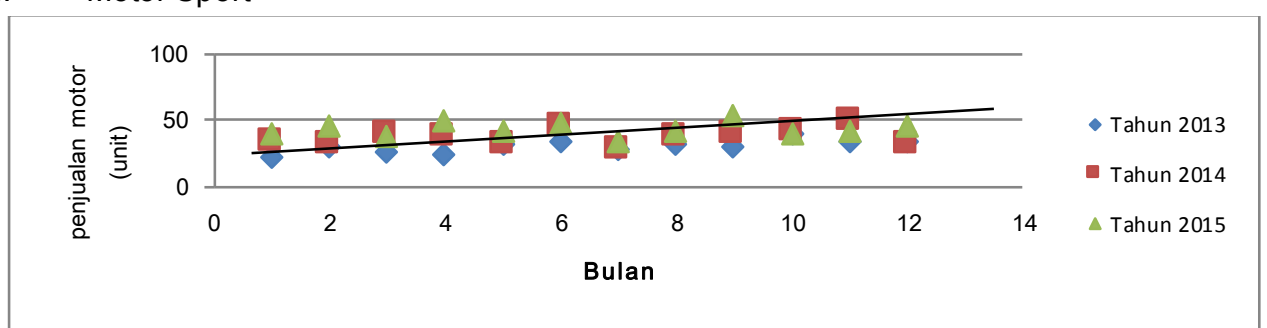

Gambar 3: Plot Data Aktual Penjualan Motor Sport

Pada uji linearitas $d$ atas terlihat bahwa titik-titik persebaran data berada disekitar garis lurus, maka data penjualan motor matik, motor bebek dan motor sport dikatakan linear.

\subsection{Perhitungan Proyeksi Menggunakan Metode Trend Analisis}

Penyelesaian Proyeksi Penjualan Motor Menggunakan Metode Trend Analisis yaitu :

a. Motor Matik

Gunakan metode kuadrat terkecil dengan rumus sebagai berikut:

$\hat{Y}=a+b X$

dimana :

$\hat{Y}=$ taksiran nilai trend

$X=$ variabel waktu

Untuk nilai $a$ dan $b$ sebagai berikut :

$$
\begin{aligned}
& b=\frac{N \sum X Y-\sum X \sum Y}{N \sum X^{2}-\left(\sum X\right)^{2}}=\frac{(36 \times 58005)-(666 \times 3036)}{(36 \times 16206)-(666)^{2}}=\frac{2088180-2021976}{583416-443556}=0,473359 \\
& a=\bar{Y}-b \bar{X}=\frac{3036}{36}-0,47 \frac{666}{36}=\frac{3036}{36}-\frac{313,02}{36}=75,64
\end{aligned}
$$

Masukan nilai $a$ dan $b$ ke persamaan (1):

$\hat{Y}=a+b X$

$=75,64+0,479(X)$

Adapun nilai galat $\varepsilon=Y-\hat{Y}$ dengan $Y$ adalah data aktual dan $\hat{Y}$ adalah nilai proyeksi.

Sehingga persamaan galat relatif yaitu (Renaldi Munir, 2006):

$\varepsilon_{R}=\frac{\varepsilon}{Y}$

Dan rata-rata galat relatif yaitu :

$\overline{\varepsilon_{R}}=\frac{\sum_{i=1}^{n} \varepsilon_{R}}{n} \times 100 \%$

Tabel 3 : Penyelesaian Proyeksi Penjualan Motor Matik

\begin{tabular}{|c|l|c|c|c|c|c|}
\hline Tahun & Bulan & Data Aktual $(Y)$ & Proyeksi & $\varepsilon$ & $|\varepsilon|$ & $\varepsilon_{R}$ \\
\hline \multirow{7}{*}{2013} & Januari & 77 & 76 & 1 & 1 & 0,01 \\
\cline { 2 - 7 } & Februari & 87 & 77 & 10 & 10 & 0,11 \\
\cline { 2 - 7 } & Maret & 68 & 77 & -9 & 9 & 0,13 \\
\cline { 2 - 7 } & April & 69 & 78 & -9 & 9 & 0,13 \\
\cline { 2 - 7 } & Mei & 74 & 78 & -4 & 4 & 0,05 \\
\cline { 2 - 7 } & Juni & 84 & 79 & 5 & 5 & 0,06 \\
\cline { 2 - 7 } & Juli & 80 & 79 & 1 & 1 & 0,01 \\
\cline { 2 - 7 } & Agustus & 87 & 79 & 8 & 8 & 0,09 \\
\hline
\end{tabular}




\begin{tabular}{|c|c|c|c|c|c|c|}
\hline & september & 70 & 80 & -10 & 10 & 0,14 \\
\hline & Oktober & 64 & 80 & -16 & 16 & 0,25 \\
\hline & November & 92 & 81 & 11 & 11 & 0,12 \\
\hline & Desember & 83 & 81 & 2 & 2 & 0,02 \\
\hline \multirow{12}{*}{2014} & Januari & 81 & 82 & -1 & 1 & 0,01 \\
\hline & Februari & 83 & 82 & 1 & 1 & 0,01 \\
\hline & Maret & 79 & 83 & -4 & 4 & 0,05 \\
\hline & April & 63 & 83 & -20 & 20 & 0,32 \\
\hline & Mei & 69 & 84 & -15 & 15 & 0,22 \\
\hline & Juni & 85 & 84 & 1 & 1 & 0,01 \\
\hline & Juli & 116 & 85 & 31 & 31 & 0,27 \\
\hline & Agustus & 97 & 85 & 12 & 12 & 0,12 \\
\hline & september & 99 & 86 & 13 & 13 & 0,13 \\
\hline & Oktober & 86 & 86 & 0 & 0 & 0 \\
\hline & November & 82 & 87 & -5 & 5 & 0,06 \\
\hline & Desember & 107 & 87 & 20 & 20 & 0,19 \\
\hline \multirow{13}{*}{2015} & Januari & 92 & 87 & 5 & 5 & 0,05 \\
\hline & Februari & 84 & 88 & -4 & 4 & 0,05 \\
\hline & Maret & 91 & 88 & 3 & 3 & 0,03 \\
\hline & April & 78 & 89 & -11 & 11 & 0,14 \\
\hline & Mei & 90 & 89 & 1 & 1 & 0,01 \\
\hline & Juni & 99 & 90 & 9 & 9 & 0,09 \\
\hline & Juli & 81 & 90 & -9 & 9 & 0,11 \\
\hline & Agustus & 82 & 91 & -9 & 9 & 0,11 \\
\hline & september & 79 & 91 & -12 & 12 & 0,15 \\
\hline & Oktober & 83 & 92 & -9 & 9 & 0,11 \\
\hline & November & 103 & 92 & 11 & 11 & 0,11 \\
\hline & Desember & 92 & 93 & -1 & 1 & 0,01 \\
\hline & Total & 3,036 & & & & 3,48 \\
\hline
\end{tabular}

Maka perhitungan rata-rata galat relatif menggunakan persamaan (3) yaitu : $\overline{\varepsilon_{R}}=\frac{\sum_{i=1}^{n} \varepsilon_{R}}{n} \times 100 \%=\frac{3,48}{36} \times 100 \%=9,7 \%$

\section{b. Motor Bebek}

Gunakan metode kuadrat terkecil dengan rumus persamaan (1) :

Untuk nilai $a$ dan $b$ sebagai berikut :

$$
\begin{aligned}
& b=\frac{N \sum X Y-\sum X \sum Y}{N \sum X^{2}-\left(\sum X\right)^{2}}=\frac{(36 \times 51063)-(666 \times 2646)}{(36 \times 16206)-(666)^{2}}=\frac{1838268-1762236}{583416-443556}=0,543629 \\
& a=\bar{Y}-b \bar{X}=\frac{2646}{36}-0,54 \frac{666}{36}=\frac{2646}{36}-\frac{359,64}{36}=63,51
\end{aligned}
$$

Masukan nilai $a$ dan $b$ ke persamaan (1):

$\hat{Y}=a+b X$

$=63,51+0,54(X)$ 
Tabel 4 : Penyelesaian Proyeksi Penjualan Motor Bebek

\begin{tabular}{|c|c|c|c|c|c|c|}
\hline Tahun & Bulan & Data Aktual $(Y)$ & Proyeksi & $\varepsilon$ & $|\varepsilon|$ & $\varepsilon_{R}$ \\
\hline \multirow{12}{*}{2013} & Januari & 65 & 64 & 1 & 1 & 0,01 \\
\hline & Februari & 71 & 65 & 6 & 6 & 0,08 \\
\hline & Maret & 44 & 65 & -21 & 21 & 0,48 \\
\hline & April & 56 & 66 & -10 & 10 & 0,18 \\
\hline & Mei & 68 & 66 & 2 & 2 & 0,03 \\
\hline & Juni & 67 & 67 & 0 & 0 & 0 \\
\hline & Juli & 76 & 67 & 9 & 9 & 0,12 \\
\hline & Agustus & 73 & 68 & 5 & 5 & 0,07 \\
\hline & september & 77 & 68 & 9 & 9 & 0,12 \\
\hline & Oktober & 60 & 69 & -9 & 9 & 0,15 \\
\hline & November & 77 & 70 & 7 & 7 & 0,09 \\
\hline & Desember & 82 & 70 & 12 & 12 & 0,15 \\
\hline \multirow{12}{*}{2014} & Januari & 64 & 71 & -7 & 7 & 0,11 \\
\hline & Februari & 82 & 71 & 11 & 11 & 0,13 \\
\hline & Maret & 67 & 72 & -5 & 5 & 0,07 \\
\hline & April & 55 & 72 & -17 & 17 & 0,31 \\
\hline & Mei & 58 & 73 & -15 & 15 & 0,26 \\
\hline & Juni & 72 & 73 & -1 & 1 & 0,01 \\
\hline & Juli & 91 & 74 & 17 & 17 & 0,19 \\
\hline & Agustus & 79 & 74 & 5 & 5 & 0,06 \\
\hline & september & 74 & 75 & -1 & 1 & 0,01 \\
\hline & Oktober & 82 & 75 & 7 & 7 & 0,08 \\
\hline & November & 80 & 76 & 4 & 4 & 0,05 \\
\hline & Desember & 98 & 77 & 21 & 21 & 0,21 \\
\hline \multirow{13}{*}{2015} & Januari & 72 & 77 & -5 & 5 & 0,07 \\
\hline & Februari & 76 & 78 & -2 & 2 & 0,03 \\
\hline & Maret & 63 & 78 & -15 & 15 & 0,24 \\
\hline & April & 59 & 79 & -20 & 20 & 0,34 \\
\hline & Mei & 79 & 79 & 0 & 0 & 0 \\
\hline & Juni & 78 & 80 & -2 & 2 & 0,03 \\
\hline & Juli & 92 & 80 & 12 & 12 & 0,13 \\
\hline & Agustus & 84 & 81 & 3 & 3 & 0,04 \\
\hline & september & 91 & 81 & 10 & 10 & 0,11 \\
\hline & Oktober & 73 & 82 & -9 & 9 & 0,12 \\
\hline & November & 69 & 82 & -13 & 13 & 0,19 \\
\hline & Desember & 92 & 83 & 9 & 9 & 0,09 \\
\hline & Total & 2646 & & & & 4,36 \\
\hline
\end{tabular}

Maka perhitungan rata-rata galat relatif menggunakan persamaan (3) yaitu :

$\overline{\varepsilon_{R}}=\frac{\sum_{i=1}^{n} \varepsilon_{R}}{n} \times 100 \%=\frac{4,36}{36} \times 100 \%=12,1 \%$ 


\section{c. Motor Sport}

Gunakan metode kuadrat terkecil dengan rumus persamaan (1) :

Untuk nilai $a$ dan $b$ sebagai berikut :

$$
\begin{aligned}
& b=\frac{N \sum X Y-\sum X \sum Y}{N \sum X^{2}-\left(\sum X\right)^{2}}=\frac{(36 \times 26169)-(666 \times 1306)}{(36 \times 16206)-(666)^{2}}=\frac{942084-869796}{583416-443556}=0,52 \\
& a=\bar{Y}-b \bar{X}=\frac{1306}{36}-0,52 \frac{666}{36}=\frac{2646}{36}-\frac{346,32}{36}=26,66
\end{aligned}
$$

Masukan nilai $a$ dan $b$ ke persamaan (1):

$\hat{Y}=a+b X$

$$
=26,66+0,52(X)
$$

\begin{tabular}{|c|c|c|c|c|c|c|}
\hline Tahun & Bulan & $\begin{array}{c}\text { Data aktual } \\
(Y)\end{array}$ & Proyeksi & $\varepsilon$ & $|\varepsilon|$ & $\varepsilon_{R}$ \\
\hline \multirow{12}{*}{2013} & Januari & 22 & 27 & -5 & 5 & 0,23 \\
\hline & Februari & 29 & 28 & 1 & 1 & 0,03 \\
\hline & Maret & 25 & 28 & -3 & 3 & 0,12 \\
\hline & April & 23 & 29 & -6 & 6 & 0,26 \\
\hline & Mei & 32 & 29 & 3 & 3 & 0,09 \\
\hline & Juni & 34 & 30 & 4 & 4 & 0,12 \\
\hline & Juli & 28 & 30 & -2 & 2 & 0,07 \\
\hline & Agustus & 31 & 31 & 0 & 0 & 0 \\
\hline & september & 29 & 31 & -2 & 2 & 0,07 \\
\hline & Oktober & 39 & 32 & 7 & 7 & 0,18 \\
\hline & November & 34 & 32 & 2 & 2 & 0,06 \\
\hline & Desember & 34 & 33 & 1 & 1 & 0,03 \\
\hline \multirow{12}{*}{2014} & Januari & 34 & 33 & 1 & 1 & 0,03 \\
\hline & Februari & 32 & 34 & -2 & 2 & 0,06 \\
\hline & Maret & 39 & 34 & 5 & 5 & 0,13 \\
\hline & April & 37 & 35 & 2 & 2 & 0,05 \\
\hline & Mei & 31 & 35 & -4 & 4 & 0,13 \\
\hline & Juni & 44 & 36 & 8 & 8 & 0,18 \\
\hline & Juli & 27 & 36 & -9 & 9 & 0,33 \\
\hline & Agustus & 36 & 37 & -1 & 1 & 0,03 \\
\hline & september & 38 & 37 & 1 & 1 & 0,03 \\
\hline & Oktober & 41 & 38 & 3 & 3 & 0,07 \\
\hline & November & 49 & 39 & 10 & 10 & 0,2 \\
\hline & Desember & 32 & 39 & -7 & 7 & 0,22 \\
\hline \multirow{8}{*}{2015} & Januari & 39 & 40 & -1 & 1 & 0,03 \\
\hline & Februari & 44 & 40 & 4 & 4 & 0,09 \\
\hline & Maret & 37 & 41 & -4 & 4 & 0,11 \\
\hline & April & 48 & 41 & 7 & 7 & 0,15 \\
\hline & Mei & 40 & 42 & -2 & 2 & 0,05 \\
\hline & Juni & 46 & 42 & 4 & 4 & 0,09 \\
\hline & Juli & 33 & 43 & -10 & 10 & 0,3 \\
\hline & Agustus & 41 & 43 & -2 & 2 & 0,05 \\
\hline
\end{tabular}

Tabel 5 : Penyelesaian Proyeksi Penjualan Motor Sport 


\begin{tabular}{|l|l|l|l|l|l|c|} 
& september & 53 & 44 & 9 & 9 & 0,17 \\
\cline { 2 - 7 } & Oktober & 39 & 44 & -5 & 5 & 0,13 \\
\cline { 2 - 7 } & November & 41 & 45 & -4 & 4 & 0,09 \\
\cline { 2 - 7 } & Desember & 45 & 45 & 0 & 0 & 0 \\
\hline & Total & 1.306 & & & & 3,98 \\
\hline
\end{tabular}

Maka perhitungan rata-rata galat relatif menggunakan persamaan (3) yaitu :

$\overline{\varepsilon_{R}}=\frac{\sum_{i=1}^{n} \varepsilon_{R}}{n} \times 100 \%=\frac{3,98}{36} \times 100 \%=11,06 \%$

Dari hasil perhitungan menggunakan metode trend analisis motor matik, motor bebek dan motor sport maka di dapatkan proyeksi penjualan motor dari bulan januari sampai bulan desember tahun 2016 sebagai berikut :

Tabel 6 : Hasil Proyeksi Penjualan Motor Tahun 2016

\begin{tabular}{|l|c|c|c|}
\hline \multicolumn{1}{|c|}{ Bulan } & Motor Matik & Motor Bebek & Motor Sport \\
\hline Januari & 93 & 84 & 46 \\
\hline Februari & 94 & 84 & 46 \\
\hline Maret & 94 & 85 & 47 \\
\hline April & 94 & 85 & 47 \\
\hline Mei & 95 & 86 & 48 \\
\hline Juni & 95 & 86 & 48 \\
\hline Juli & 96 & 87 & 49 \\
\hline Agustus & 96 & 87 & 49 \\
\hline September & 97 & 88 & 50 \\
\hline Oktober & 97 & 88 & 50 \\
\hline November & 98 & 89 & 51 \\
\hline Desember & 98 & 89 & 51 \\
\hline
\end{tabular}

Adapun data aktual penjualan motor yamaha tahun 2016 bulan januari-agustus yang disajikan sebagai berikut:

Tabel 7 : Data Aktual Penjualan Motor Tahun 2016

\begin{tabular}{|l|c|c|c|}
\hline Bulan & Motor Matik & Motor Bebek & Motor Sport \\
\hline Januari & 94 & 85 & 47 \\
\hline Februari & 98 & 89 & 43 \\
\hline Maret & 91 & 83 & 56 \\
\hline April & 99 & 81 & 50 \\
\hline Mei & 102 & 87 & 53 \\
\hline Juni & 96 & 95 & 48 \\
\hline Juli & 99 & 90 & 42 \\
\hline Agustus & 104 & 88 & 58 \\
\hline
\end{tabular}

\subsection{Keuntungan Perusahaan}

Dengan menjumlahkan perkalian penjualan motor dan keuntungan setiap unitnya maka kuntungan yang diperoleh perusahaan perbulan tahun 2016 yaitu bulan Januari Rp.269.000.000, Februari Rp.270.000.000, Maret dan April Rp.273.000.000, Mei dan Juni 
Rp. 277.000.000, Juli dan Agustus Rp. 281.000.000, September dan Oktober Rp. 285.000.000, November dan Desember Rp. 289.000.000.

\section{KESIMPULAN}

Berdasarkan penelitian dan uraian pada bab-bab sebelumnya maka penulis dapat menarik kesimpulan bahwa

1. Dengan menggunakan metode Trend Analisis diperoleh penjulan motor tahun 2016 sebagai berikut :

\begin{tabular}{|l|c|c|c|}
\hline Bulan & Motor Matik & Motor Bebek & Motor Sport \\
\hline Januari & 93 & 84 & 46 \\
\hline Februari & 94 & 84 & 46 \\
\hline Maret & 94 & 85 & 47 \\
\hline April & 94 & 85 & 47 \\
\hline Mei & 95 & 86 & 48 \\
\hline Juni & 95 & 86 & 48 \\
\hline Juli & 96 & 87 & 49 \\
\hline Agustus & 96 & 87 & 49 \\
\hline September & 97 & 88 & 50 \\
\hline Oktober & 97 & 88 & 50 \\
\hline November & 98 & 89 & 51 \\
\hline Desember & 98 & 89 & 51 \\
\hline
\end{tabular}

2. Adapun keuntungan perusahaan di tahun 2016 yaitu bulan Januari Rp. 269.000.000, Februari Rp.270.000.000, Maret dan April Rp.273.000.000, Mei dan Juni Rp.277.000.000, Juli dan Agustus Rp.281.000.000, September dan Oktober Rp. 285.000.000, November dan Desember Rp. 289.000.000.

\section{DAFTAR PUSTAKA}

[1] Fitria Sari, Analisis Triple Exponential Smoothing Untuk Peramalan Volume Penjualan Motor Pada PT. Sentral Yamaha Palu, Universitas Tadulako, 2009, Palu.

[2] Ginting, R. Sistem Produksi. PT. Graha IImu, 2007, Yogjakarta.

[3] Makridakis, S., Wheelwright, S.C., dan McGee, V. E. Metode dan Aplikasi Peramalan, Erlangga, 1999, Jakarta.

[4] Renaldi Munir, Metoda numerik, Penerbit Informatika, 2006, Bandung.

[5] Vera Devani, Optimasi Perencanaan Produksi dengan Menggunakan Metode Goal Programming. Fakultas Sains dan teknologi Universitas Islam Negeri Sultan Syarif Kasim Riau, 2010. 